\title{
Bovine trypanosomosis in the Upper West Region of Ghana: Entomological, parasitological and serological cross-sectional surveys
}

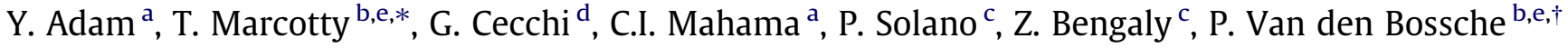 \\ ${ }^{a}$ Veterinary Services Department of MOFA, P.O. Box 97, Pong-Tamale, Ghana \\ ${ }^{\mathrm{b}}$ Institute of Tropical Medicine (ITM), Animal Health Department, Nationalstraat 155, Antwerp, Belgium

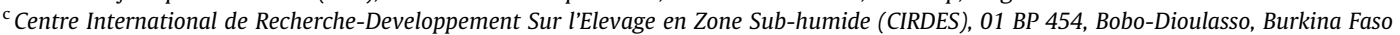 \\ ${ }^{\mathrm{d}}$ Food and Agriculture Organization of the United Nations (FAO), Animal Production and Health Division, Viale delle Terme di Caracalla, 00153 Rome, Italy \\ e Department of Veterinary Tropical Diseases, University of Pretoria, Private Bag X04, Onderstepoort, South Africa
}

\section{A R T I C L E I N F O}

\section{Article history:}

Received 20 October 2010

Accepted 8 April 2011

Available online $\mathrm{xxxx}$

\section{Keywords:}

Survey

Trypanosomosis

Glossina

Ghana

Prevalence

Bovine

PATTEC

\begin{abstract}
A B S T R A C T
Baseline surveys were conducted in the Upper West Region of Ghana to assess the distribution and densities of tsetse species, as well as the prevalence of bovine trypanosomosis. The entomological survey was designed to cover the suitable tsetse habitats along the three main rivers in the study area (i.e. Black Volta, Kulpawn and Sissili). Results indicated the presence of Glossina tachinoides in all three river basins, whilst Glossina palpalis gambiensis was only found close to the southern limit of the study area. A random sampling of 1800 cattle of the West African Short Horn, Sanga and Zebu breeds from 36 randomly selected grid cells covering the study area showed substantial differences between parasitological and serological prevalences. The average parasitological prevalence was estimated at $2.5 \%$ (95\% CI: $1.06-$ 5.77) with the majority of the infections due to Trypanosoma vivax. Most of the infected cattle were found close to the major river systems. The serological prevalence, measured using Enzyme Linked Immunosorbent Assay (ELISA), test was 19\% (95\% CI: 14.03-25.35). Cattle with anti-trypanosomal antibodies were also found throughout the study area.
\end{abstract}

(c) 2011 Elsevier Ltd. All rights reserved.

\section{Introduction}

Trypanosomosis is a haemoprotozoan disease, mostly transmitted by the tsetse fly (Glossina spp.), which cause severe disease in humans and livestock in sub-Saharan Africa. The disease results in loss of livestock and agricultural productivity with serious socio-economic consequences (Swallow, 2000). The occurrence of tsetse species within different climatic zones and vegetation types in Ghana were studied by various researchers. In the drier, northern parts of the country Glossina palpalis gambiensis was found to coexist, at comparatively lower densities, with Glossina tachinoides (Nash, 1948). In these areas, suitable land cover for tsetse flies was represented by open woodland and rangeland, mostly clustered along the main rivers (Black Volta, Kulpawn and Sissili) and their tributaries. Both G. palpalis gambiensis and G. tachinoides belong to the palpalis group. They play a role in the transmission of both human and animal trypanosomosis and can adapt to high human

\footnotetext{
* Corresponding author at: Institute of Tropical Medicine (ITM), Animal Health Department, Nationalstraat 155, 2000 Antwerp, Belgium. Tel.: +32 3 2476263; fax: +32 32476268 .

E-mail address: tmarcotty@itg.be (T. Marcotty).

Died in Antwerp on 11 November 2010.
}

densities (Solano et al., 2010; Courtin et al., 2009). By contrast, Glossina morsitans submorsitans and Glossina longipalpis (morsitans group) were found to be associated with game animals in open woodland savannah. In the transitional forest zone, G. longipalpis was said to be present whereas in the forested southern part of the country, tsetse species of the fusca group (Glossina fusca, Glossina nigrofusca, Glossina tabaniformis and Glossina medicorum) (Offori, 1964) were present.

In the past, the persistence of this trans-boundary disease has certainly been enhanced by the lack of a concerted, multi-national approach. The "Pan-African Tsetse and Trypanosomosis Eradication Campaign" (PATTEC) was therefore established by the African Union in the year 2000 aiming at eradicating tsetse and trypanosomosis from Africa by bringing together the efforts of all affected countries. Under the PATTEC initiative, Ghana, Burkina Faso and Mali initiated a project to create tsetse-free areas within their common tsetse fly belt. Whilst the epidemiological situation of human African trypanosomosis in the region has recently been reviewed (Cecchi et al., 2009; Simarro et al., 2010) there is a need to clarify the current prevalence of animal trypanosomosis and the distribution of tsetse flies, to facilitate the making of sound decisions in the campaign. The main aim of this field-based research work is therefore to provide information on the prevalence of trypanosomes and 
its vector to guide decision making in project implementation, as well as to generate sound baseline data for monitoring and evaluation.

The Upper West Region in Ghana was chosen as project area for the first phase of the Ghana component of the PATTEC initiative based on economic (i.e. potential for high economic return; Shaw et al., 2006), entomological (i.e. proximity to the northern tsetse distribution limits) and strategic criteria referring to the geographic location of the three national projects in West Africa. The study area is bordered to the North and West by Burkina Faso. It is sub-divided into 8 districts. The climate of the study area is tropical with a single rainy season from May to October, followed by a long dry season from November to April.

Three main breeds of cattle are found here: the West African Shorthorn (WASH), Zebu and Sanga. The WASH is the most common breed of cattle raised in the area because of its high trypano-tolerance as compared to the other two breeds (Mahama et al., 2003). Of the three breeds of cattle, the Zebu is the most susceptible to trypanosomosis and the least represented in the total cattle population of the area. The zebu cattle are found mainly in the North-eastern corridors of the Upper West Region (Sissala Districts), where the tsetse population is comparatively less dense (Mahama et al., 2003). Cattle in the Upper West Region are mostly herded by Fulani immigrants, acting as paid employees, from neighbouring countries north of Ghana. The husbandry system is sedentary with communal grazing along rivers, shuttling from settlements to the main peri-riparian grazing areas, usually located in a radius of 2-5 km (Mahama, 2005). The practice of transhumance is also occasionally encountered in the area. Indeed, it is not infrequent to observe cattle from Burkina Faso cross the Black Volta River for grazing in and outside the study area.

\section{Materials and methods}

\subsection{Study area}

The study area, the Upper West Region, is located in the Volta basin, in the North-western corner of Ghana between latitude $9.62-11^{\circ} \mathrm{N}$ and longitude $1.40-2.76^{\circ} \mathrm{W}$. The Black Volta River represents the natural border with Burkina Faso. The total surface of the Upper West Region is approximately $18,000 \mathrm{~km}^{2}$.

\subsection{Entomological surveys}

A cross-sectional tsetse fly survey was conducted along the three main rivers of the Upper West Region (Black Volta, Kulpawn, and Sissili Rivers), during dry seasons (April-May 2008 and December 2008-March 2009). At this time of the year, and due mainly to annual bush fires, vegetation in the Upper West Region is reduced to patches of riparian vegetation along the main river banks. In view of this and because of logistical constraints associated with sampling the entire river basins, trapping was restricted to the main rivers where riparian vegetation was present based on satellite images and visual inspection in the field. Hence, trapping sites were interspaced with open and often cultivated river banks unsuitable for tsetse (de la Rocque et al., 2001).

Apart from the Black Volta River, which holds water throughout the year and provides ample habitat for tsetse, the other main rivers, Kulpawn and Sissili, are extensively silted and provide little potential habitat for tsetse flies. Biconical traps (Challier et al., 1977) were deployed in the suitable riparian vegetation and at cattle watering points. An average of 20 traps was deployed at each site at $200 \mathrm{~m}$ spacing. The location of each trap was recorded with a Global Positioning System (GPS). A total of 564 traps were deployed along the three rivers. Traps deployed at 8 am were recov- ered the following day at the same time, having been inspected twice within that period. Thus, tsetse flies were collected twice daily and the number, species and sex of flies caught determined and recorded. An index of apparent abundance (IAA) of tsetse was calculated as the number of flies (males and females) caught per trap per trapping day.

\subsection{Parasitological and serological survey of bovine trypanosomosis}

\subsubsection{Sampling framework}

To determine the prevalence of livestock trypanosomosis, the study area was divided into 180 grid cells of $10 \mathrm{~km} \times 10 \mathrm{~km}$. Grid cells that on the basis of census figures appeared not to host enough cattle were left out. With the aid of a computer-generated random table, 36 out of the 148 grid cells were selected. These 36 grid cells had total cattle population of 11,531 animals, out of which 1800 cattle were selected (50 cattle from each of the grid cells). The 50-head sample represents the average size of a cattle herd in the area. Moreover, a sample size of 50 animals provides a $95 \%$ certainty of detecting at least one positive trypanosomosis case at a prevalence of $5 \%$ (Cannon and Roe, 1982). For the purpose of sample collection, and because of the communal grazing system practiced in Ghana, we considered all herds of cattle in a village as one herd. A village with cattle in each of the 36 grid cells was thus selected for sampling by a computer generated random table. Where the randomly selected herd could not give the required 50 cattle, the balance was obtained from a herd of another randomly selected village within the same grid cell. Transhumant cattle were not considered because their kraals and locations would not fit in the sampling framework.

\subsubsection{Sampling and processing}

The location of each sampling site, normally located in the vicinity of the herd's village, was determined using a GPS, and the relevant coordinates were used to map the distribution of bovine trypanosomosis. At each sampling site, blood samples were obtained from the jugular vein into heparinised tubes. Each animal was classified by breed, sex and age, the latter based on two categories: adult ( $\geqslant 3$ years), and young ( $<3$ years). Two heparinised capillary tubes were filled for each sample and centrifuged for $5 \mathrm{~min}$ at $9000 \mathrm{~g}$. The packed cell volume (PCV) was measured and recorded. The Buffy coat and the uppermost layer of red blood cells of each sample were extruded onto a microscope slide and examined for trypanosome parasites under a compound microscope using the Buffy coat technique (Murray et al., 1977). The plasma was collected on a filter paper, (Whatman No. 4, Whatman Ltd.) for further serological examination.

\subsubsection{Serological diagnosis}

Anti-trypanosomal antibody detection in the plasma on the filter papers was performed using an Enzyme Linked Immunosorbent Assay (ELISA). Plasma spots on filter paper were eluted in $1.5 \mathrm{ml}$ of phosphate buffered saline (PBS) containing $0.1 \%$ Tween 20 for $2 \mathrm{~h}$ on a rotation shaker. Three indirect antibody ELISAs were performed on each sample using antigens of Trypanosoma vivax (Zaria 81/699), Trypanosoma congolense (IL1180) and Trypanosoma brucei (Desquesnes et al., 2001). The sensitivities of these three tests, under controlled conditions, were above $90 \%$ in experimentally infected sheep and in non-infected cattle specificity was above $99 \%$ (Desquesnes et al., 2001). The absorbance values were determined by photometry on an ELISA plate reader (Labsystem Multiskan MCC/340) using a $405 \mathrm{~nm}$ filter and interfaced to a desktop computer. For each type of antibody ELISA (ELISA - T. vivax, ELISA T. brucei and ELISA - T. congolense), results were expressed in the Relative Percentage Positivity (RPP). Samples with RPP value exceeding the mean RPP of negative samples plus three standard 
deviations were considered seropositive (Desquesnes et al., 2001).

\subsubsection{Statistical analysis}

For each grid cell, the average PCV of the sampled cattle and its standard deviation were calculated. In addition, the average and confidence intervals of the parasitological and serological prevalence were calculated for each grid cell using a binomial distribution or the exact method when the prevalence was null. The overall parasitological and serological prevalence parameters were estimated in a robust logistic regression in Stata 10 (StataCorp., 2009). The grid cells were considered as primary sampling units and were given their cattle population as weight. The proportion of grid cells selected was used as a finite population correction factor. The data were further analysed in similar models using the animals' breed (WASH, Zebu or Sanga), sex and age classes, and the interactions between them as discrete explanatory variables. The relation between the PCV and the animals' breed, sex, age class, parasitological and serological status was first evaluated in a stepwise backward selection of estimators $(p<0.1)$. The distribution of the residuals of the retained model was assessed in a $\mathrm{Q}-\mathrm{Q}$ plot. The data were then analysed in a robust linear regression, using the retained estimators and the interaction between them as discrete explanatory variables. Primary sampling units, weights and finite population correction factors were as above.

\section{Results}

\subsection{Distribution of Glossina species in the study area}

A total of 3561 tsetse flies were caught (Table 1). Flies caught on the first day of the survey ( 482 flies) were lost before their sex and species could be determined. The tsetse survey revealed the presence of two Glossina species i.e. G. tachinoides and G. palpalis gambiensis. G. tachinoides was caught adjacent to the three main rivers of the Upper West Region, and thus appears to be distributed throughout the study area (Fig. 1). The highest values of apparent abundance were found in the South-western tip of the Upper West Region, along the Black Volta River (IAA > 100). By contrast, G. palpalis gambiensis was absent from most of the study area, and flies of this species were only found at its extreme South, along the Kulpawn and Black Volta River basins (Fig. 1). The mean IAA of tsetse was 8.7, 1.9 and 1.3 for samples taken along the Black Volta, Kulpawn and Sissili Rivers, respectively.

\subsection{Prevalence of bovine trypanosomosis based on serological and parasitological examination}

The parasitological and serological prevalence of bovine trypanosomosis in each of the grids of the Upper West Region are presented in Table 2 and Fig. 2. Trypanosomal infections were

Table 1

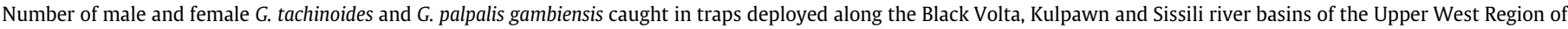
Ghana and index of apparent abundance (IAA) of tsetse along each river basin.

\begin{tabular}{|c|c|c|c|c|c|c|c|c|}
\hline \multirow[t]{3}{*}{ River basin } & \multirow{3}{*}{$\begin{array}{l}\text { Number of traps } \\
\text { deployed }\end{array}$} & \multirow{3}{*}{$\begin{array}{l}\text { Number of traps } \\
\text { with captures }\end{array}$} & \multicolumn{4}{|c|}{ Number of tsetse captured } & \multirow{3}{*}{$\begin{array}{l}\text { Undetermined } \\
\text { species and sex }\end{array}$} & \multirow[t]{3}{*}{ IAA } \\
\hline & & & \multicolumn{2}{|c|}{ G. tachinoides } & \multicolumn{2}{|c|}{ G. palpalis gambiensis } & & \\
\hline & & & Male & Female & Male & Female & & \\
\hline Black Volta & 375 & 220 & 1301 & 1415 & 13 & 36 & 482 & 8.7 \\
\hline Kulpawn & 119 & 39 & 110 & 99 & 5 & 11 & 0 & 1.9 \\
\hline Sissili & 70 & 22 & 37 & 52 & 0 & 0 & 0 & 1.2 \\
\hline Total & 564 & 281 & 1448 & 1566 & 18 & 47 & 482 & \\
\hline
\end{tabular}

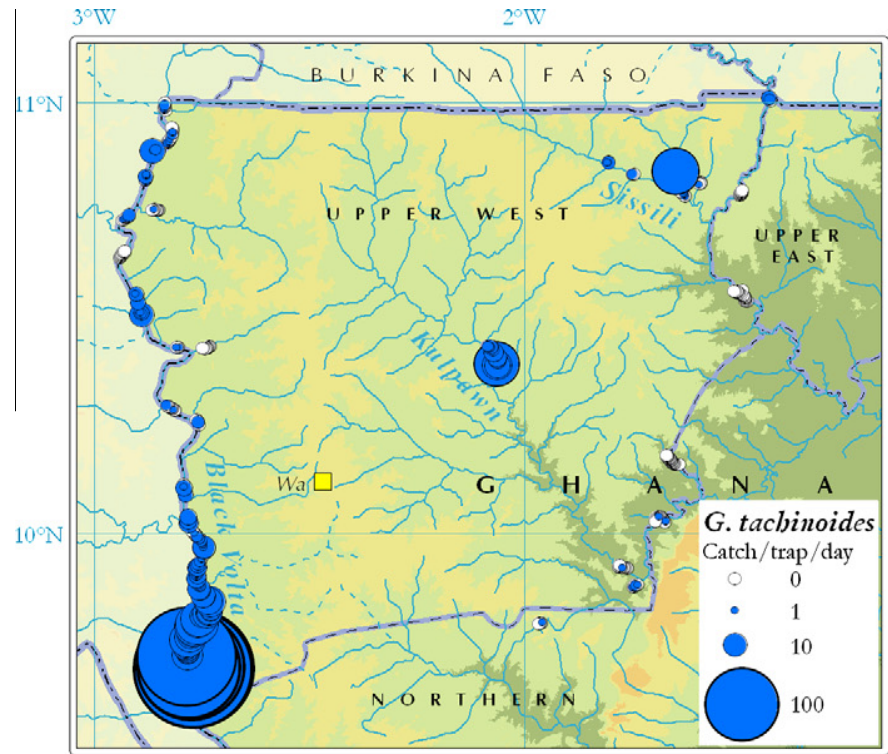

Geographic projection

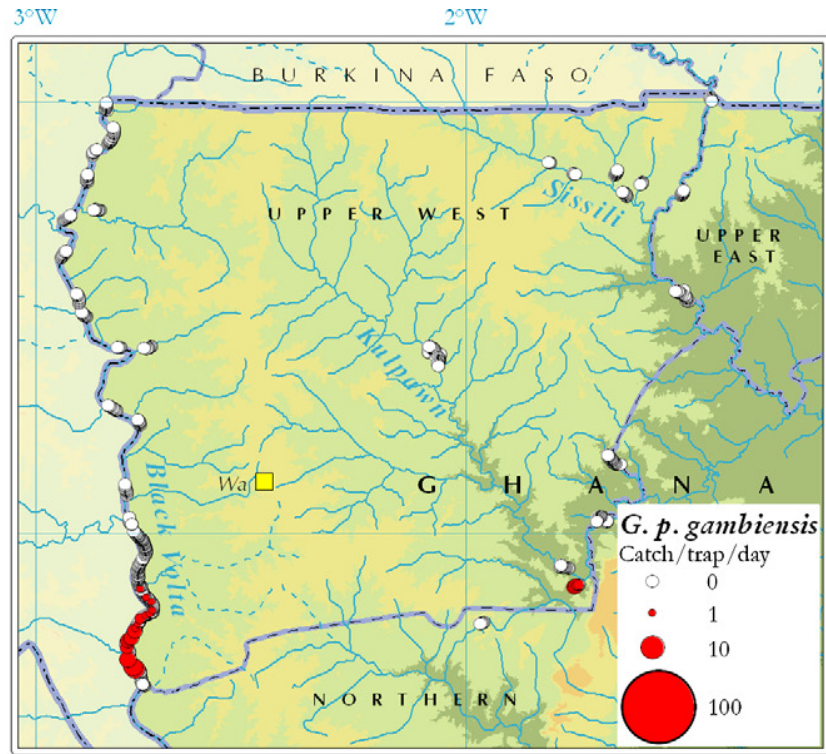

पा I I

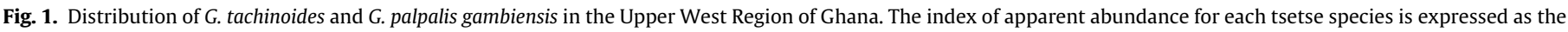
number of flies captured per trap per day. 
Table 2

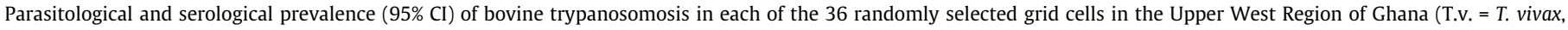
T.c. $=T$. congolense and T.b. $=T$. brucei .

\begin{tabular}{|c|c|c|c|c|c|c|c|c|c|c|c|c|}
\hline \multirow[t]{2}{*}{$\begin{array}{l}\text { Grid } \\
\text { ID }\end{array}$} & \multirow[t]{2}{*}{ Village } & \multirow[t]{2}{*}{$\begin{array}{l}\text { Number } \\
\text { sampled }\end{array}$} & \multicolumn{3}{|c|}{ Cattle breed } & \multirow[t]{2}{*}{$\begin{array}{l}\text { Average PCV } \\
\text { (in\%) } \pm \text { std }\end{array}$} & \multicolumn{3}{|c|}{$\begin{array}{l}\text { Number } \\
\text { infected }\end{array}$} & \multirow{2}{*}{$\begin{array}{l}\text { Parasitological } \\
\text { prevalence } \times 100 \\
(95 \% \mathrm{CI})\end{array}$} & \multirow[t]{2}{*}{$\begin{array}{l}\text { Number sero- } \\
\text { positives }\end{array}$} & \multirow{2}{*}{$\begin{array}{l}\text { Serological } \\
\text { prevalence } \times 100 \\
(95 \% \mathrm{CI})\end{array}$} \\
\hline & & & WASH & Sanga & Zebu & & T.v. & T.b. & T.c. & & & \\
\hline G1 & Furo & 50 & 50 & 0 & 0 & $33.6 \pm 4.7$ & 0 & 0 & 0 & $0(<5.8)$ & 3 & $6(1.9-17)$ \\
\hline G2 & Yipelle & 50 & 49 & 1 & 0 & $29.7 \pm 5.0$ & 0 & 1 & 0 & $2(0.3-12.9)$ & 1 & $2(0.3-12.9)$ \\
\hline G3 & Tokali & 50 & 28 & 22 & 0 & $30.1 \pm 6.8$ & 3 & 0 & 0 & $6(1.9-17)$ & 23 & $46(32.8-59.8)$ \\
\hline G4 & Nambeg & 50 & 39 & 11 & 0 & $30.3 \pm 5.0$ & 0 & 0 & 0 & $0(<5.8)$ & 15 & $30(19-44)$ \\
\hline G5 & Kpesiin & 50 & 37 & 5 & 8 & $29.6 \pm 5.8$ & 0 & 0 & 0 & $0(<5.8)$ & 8 & $16(8.2-28.9)$ \\
\hline G6 & Banwo & 50 & 3 & 47 & 0 & $29.2 \pm 4.1$ & 0 & 0 & 0 & $0(<5.8)$ & 0 & $0(<5.8)$ \\
\hline G7 & Joripeti & 50 & 50 & 0 & 0 & $30.1 \pm 4.1$ & 0 & 0 & 0 & $0(<5.8)$ & 0 & $0(<5.8)$ \\
\hline G8 & Eggu & 50 & 24 & 26 & 0 & $32.9 \pm 4.9$ & 1 & 0 & 0 & $2(0.3-12.9)$ & 0 & $0(<5.8)$ \\
\hline G9 & Sawale & 50 & 16 & 32 & 2 & $33.8 \pm 4.8$ & 1 & 0 & 0 & $2(0.3-12.9)$ & 0 & $0(<5.8)$ \\
\hline G10 & Gyanvu & 50 & 36 & 12 & 2 & $32.9 \pm 5.4$ & 0 & 0 & 0 & $0(<5.8)$ & 0 & $0(<5.8)$ \\
\hline G11 & Konguo & 50 & 19 & 30 & 1 & $29.3 \pm 4.5$ & 0 & 0 & 0 & $0(<5.8)$ & 9 & $18(9.6-31.1)$ \\
\hline G12 & Yaasoyi & 50 & 23 & 27 & 0 & $29.0 \pm 6.4$ & 0 & 0 & 0 & $0(<5.8)$ & 7 & $14(6.8-26.6)$ \\
\hline G13 & Kpaguri & 50 & 0 & 50 & 0 & $32.5 \pm 6.0$ & 1 & 0 & 0 & $2(0.3-12.9)$ & 9 & $18(9.6-31.1)$ \\
\hline G14 & Nyuglu & 50 & 13 & 36 & 1 & $31.0 \pm 5.1$ & 2 & 0 & 0 & $4(1-14.6)$ & 0 & $0(<5.8)$ \\
\hline G15 & Kaa & 50 & 17 & 31 & 2 & $30.6 \pm 6.1$ & 0 & 0 & 0 & $0(<5.8)$ & 5 & $10(4.2-21.9)$ \\
\hline 516 & Dinaso & 50 & 0 & 50 & 0 & $33.9 \pm 4.4$ & 2 & 0 & 0 & $4(1-14.6)$ & 24 & $48(34.6-61.7)$ \\
\hline G17 & Jang & 50 & 17 & 33 & 0 & $31.3 \pm 6.2$ & 1 & 0 & 0 & $2(0.3-12.9)$ & 18 & $36(24-50.1)$ \\
\hline G18 & Naro & 50 & 0 & 46 & 4 & $30.0 \pm 5.8$ & 1 & 0 & 0 & $2(03-12.9)$ & 17 & $34(22.3-48)$ \\
\hline G19 & Guri & 50 & 13 & 30 & 7 & $27.1 \pm 5.8$ & 0 & 0 & 0 & $0(<5.8)$ & 21 & $42(29.2-55.9)$ \\
\hline G20 & Bilingu & 50 & 50 & 0 & 0 & $33.5 \pm 3.6$ & 1 & 0 & 0 & $2(0.3-12.9)$ & 9 & $18(9.6-31.1)$ \\
\hline G21 & Vieto & 50 & 0 & 7 & 43 & $32.5 \pm 4.4$ & 0 & 1 & 0 & $2(0.3-12.9)$ & 22 & $44(32.8-59.8)$ \\
\hline G22 & Bullu & 50 & 1 & 41 & 8 & $29.2 \pm 5.0$ & 0 & 0 & 0 & $0(<5.8)$ & 32 & $64(49.9-76)$ \\
\hline G23 & Joliyiri & 50 & 15 & 35 & 0 & $35.3 \pm 5.7$ & 3 & 0 & 0 & $6(1.9-17)$ & 3 & $6(1.9-17)$ \\
\hline G24 & Chasia & 50 & 6 & 44 & 0 & $30.5 \pm 4.7$ & 0 & 0 & 0 & $0(<5.8)$ & 2 & $4(1-14.6)$ \\
\hline G25 & Sagla & 50 & 10 & 50 & 0 & $31.7 \pm 4.7$ & 3 & 0 & 0 & $6(1.9-17)$ & 10 & $20(11.1-33.3)$ \\
\hline G26 & Tiisa & 50 & 18 & 32 & 0 & $30.8 \pm 6.2$ & 0 & 0 & 0 & $0(<5.8)$ & 15 & $30(19-44)$ \\
\hline G27 & Wahab & 50 & 16 & 34 & 0 & $31.4 \pm 6.2$ & 1 & 0 & 0 & $2(0.3-12.9)$ & 14 & $28(17.3-41.9)$ \\
\hline G28 & Jijen & 50 & 40 & 10 & 0 & $28.9 \pm 4.7$ & 1 & 2 & 0 & $6(1.9-17)$ & 8 & $16(8.2-28.9)$ \\
\hline G29 & Gorima & 50 & 0 & 50 & 0 & $29.6 \pm 5.9$ & 6 & 1 & 0 & $14(6.8-26.6)$ & 19 & $38(25.7-52)$ \\
\hline G30 & Dolinda & 50 & 34 & 16 & 0 & $27.4 \pm 4.7$ & 0 & 0 & 0 & $0(<5.8)$ & 19 & $38(25.7-52)$ \\
\hline G32 & Nabulu & 50 & 28 & 22 & 0 & $29.9 \pm 4.5$ & 0 & 0 & 0 & $0(<5.8)$ & 0 & $0(<5.8)$ \\
\hline G33 & Dolibiz & 50 & 24 & 24 & 2 & $31.6 \pm 50$ & 0 & 0 & 0 & $0(<5.8)$ & 2 & $4(1-14.6)$ \\
\hline G34 & Sombis & 50 & 29 & 21 & 0 & $33.4 \pm 4.9$ & 0 & 1 & 0 & $2(0.3-12.9)$ & 1 & $2(0.3-12.9)$ \\
\hline G35 & Fachub & 50 & 41 & 9 & 0 & $29.9 \pm 9.9$ & 0 & 1 & 0 & $2(0.3-12.9)$ & 8 & $16(8.2-28.9)$ \\
\hline G36 & Pina & 50 & 32 & 17 & 1 & $30.0 \pm 5.2$ & 0 & 0 & 0 & $0(<5.8)$ & 11 & $22(12.6-35.5)$ \\
\hline \multirow[t]{2}{*}{ G37 } & Guosi & 50 & 36 & 13 & 1 & $26.6 \pm 3.7$ & 0 & 0 & 0 & $0(<5.8)$ & 7 & $14(6.8-26.6)$ \\
\hline & Totals & 1800 & 814 & 904 & 82 & & 27 & 7 & $\mathbf{0}$ & & 342 & \\
\hline
\end{tabular}

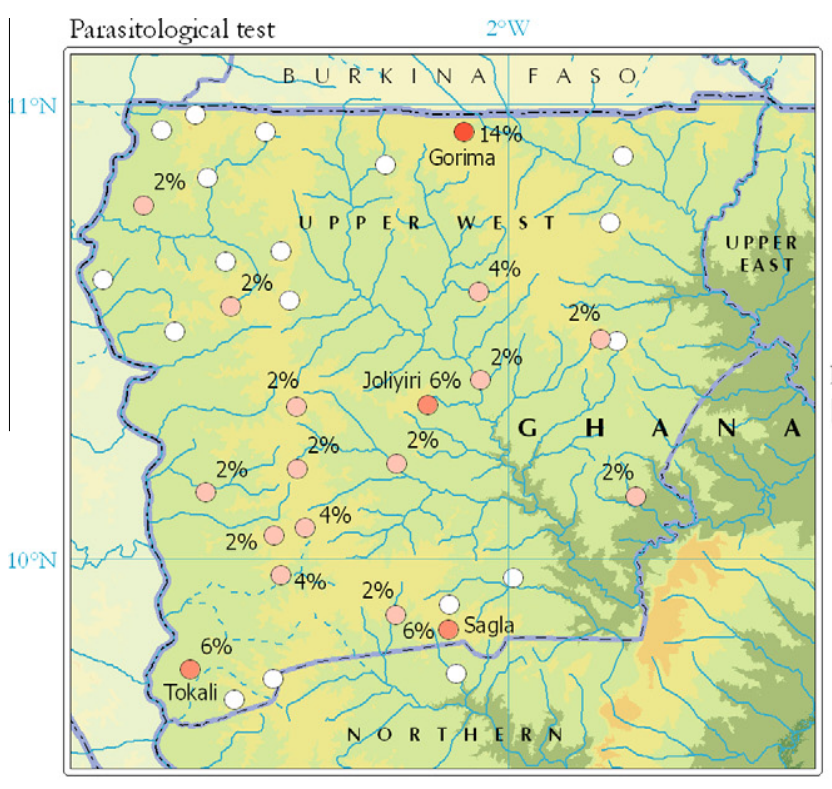

Geographic projection

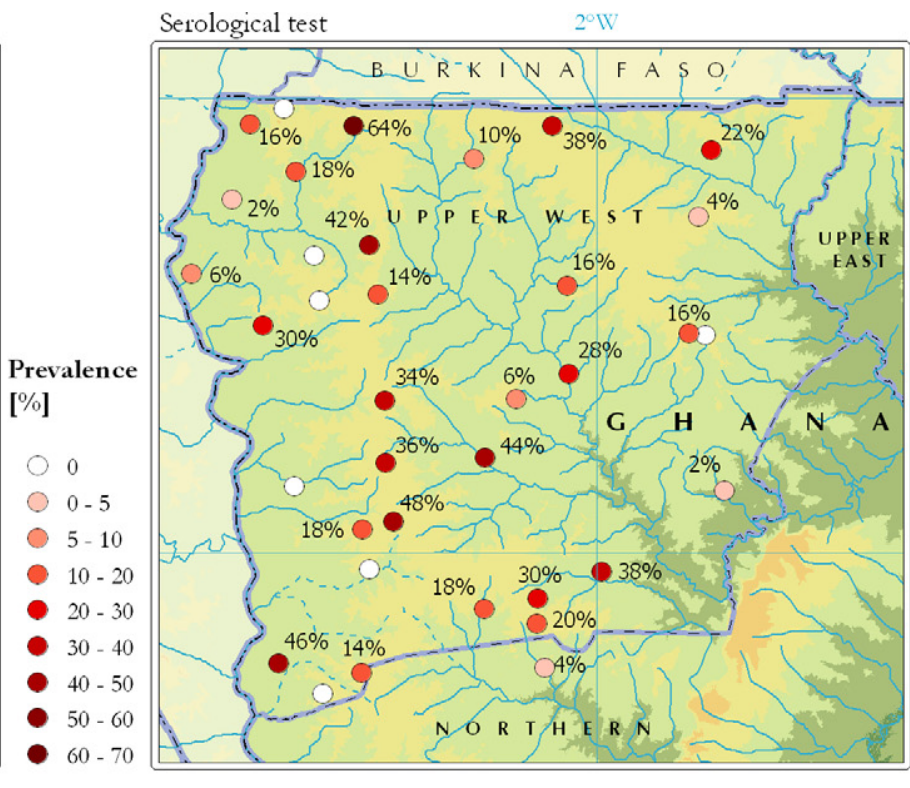

Kilometres $0 \begin{array}{lllll}10 & 20 & 30 & 40\end{array}$

Fig. 2. Parasitological and serological prevalences of livestock trypanosomosis in 36 randomly selected sampling grids in the Upper West Region of Ghana. 
detected in cattle from 18 of the 36 selected grids. The average parasitological prevalence was $2.5 \%$ (95\% CI: $1.1-5.8)$. Only infections with $T$. vivax (27) and T. brucei (7) were detected parasitologically. The parasitological prevalence of trypanosomal infections was highest in the Sanga breed. Anti-trypanosomal antibodies were detected in cattle sampled in 29 of the 36 grids (Fig. 2). In all grids, the serological prevalence of trypanosomal infections was substantially higher compared to the parasitological prevalence. The average prevalence of anti-trypanosomal antibodies was 19\% (95\% CI: 14-25). The prevalence of anti-trypanosomal antibodies was highest in adult animals of the Zebu breed (Fig. 3). The average PCV of the WASH, the Sanga and Zebu cattle was 30\%, 31\% and 32\%, respectively (Table 2 ). The PCV did not differ significantly between parasitologically positive and negative animals ( $p=0.4$ in stepwise backward selection of estimators). Little variations were observed between PCV values in seropositive and seronegative animals of the WASH and Zebu breeds (Fig. 3). In Sanga breed cattle, on the other hand, the average PCV of seropositive animals was lower $(p=0.01$ in females and 0.1 in males; Fig. 3 ).

\section{Discussion}

Three tsetse species (i.e. G. palpalis, G. tachinoides and G. morsitans) have been reported in the northern part of Ghana (Buxton, 1955; Ford, 1971). Results from the survey only revealed the presence of $G$. palpalis and G. tachinoides with $G$. tachinoides being present at the highest apparent density and distributed over a broader area.

The restricted distribution of G. palpalis gambiensis broadly follows the predictive distribution maps of this species in the region (Wint and Rogers, 2000; Wint, 2001). However, failure to detect $G$. palpalis gambiensis in the most northern section of the Upper West Region suggests a tendency towards a southerly retreat of this species.

Tsetse flies have specific ecological requirements that differ between species (Buxton, 1955). G. palpalis gambiensis lives in forests where optimal atmospheric conditions can be maintained (Challier, 1973). These forests include the gallery forests along the Black Volta River. Hence, the disturbance of the riverine forests along the

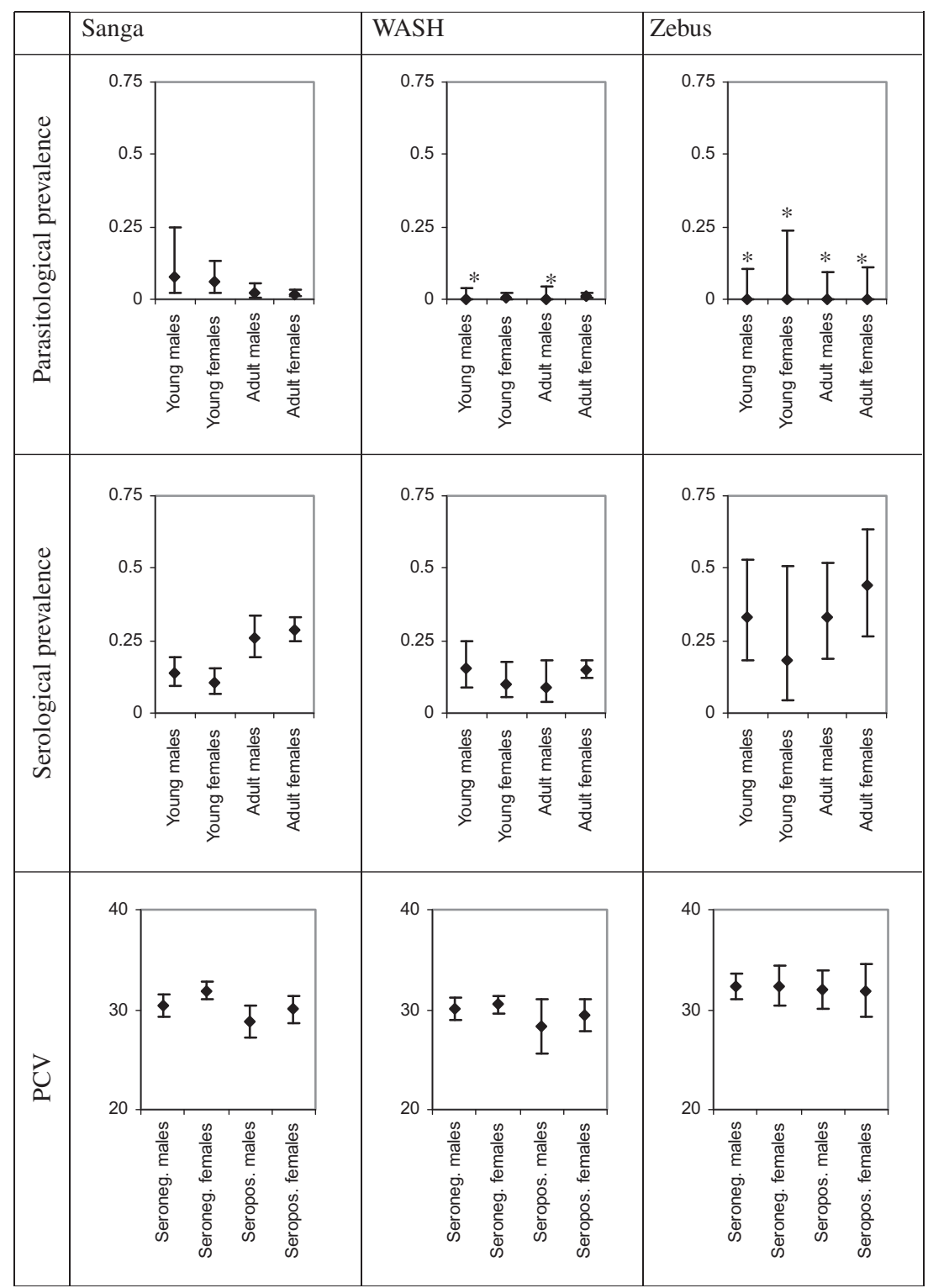

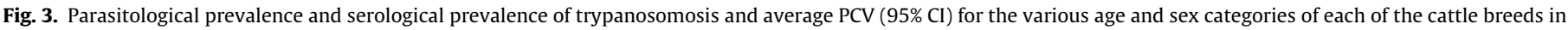
the Upper West Region of Ghana. *Estimated using an exact method (prevalence $=0$ ). 
Black Volta River and other rivers in the study area and beyond significantly reduce the suitable habitat of $G$. palpalis gambiensis, sometimes leading to the complete disappearance of the species (de La Rocque et al., 2001; Guerrini et al., 2008). According to the distribution models, the entire study area is predicted to be suitable for G. tachinoides (Wint and Rogers, 2000; Wint, 2001). Contrary to G. palpalis gambiensis, G. tachinoides can cope with more open vegetation (Laveissière, 1976) and is less affected by anthropogenic changes of the vegetation (de La Rocque et al., 2001; Van den Bossche et al., 2010). Nevertheless, the observed distribution of G. tachinoides is possibly more patchy and the apparent density highest close to the river basins.

Results of the parasitological and serological tests indicate that trypanosomosis is widespread in the study area. However, the parasitological prevalence of trypanosomal infections is generally lower than the parasitological prevalence of trypanosomal infections in cattle in the Savelugu and West Maprusi Districts of Northern Ghana (Mahama et al., 2004). This is most likely due to low tsetse challenge because of the patchy distribution of tsetse although the regular use of trypanocidal drugs cannot be excluded. The dominance of $T$. vivax infections is in line with observations made in northern Ghana and elsewhere in the region (Mahama et al., 2004; Bengaly et al., 1998). With the exception of Sagla, all villages with a parasitological prevalence of bovine trypanosomosis $>5 \%$ (Tokali, Joliyiri and Gorima) were located close to areas with relatively high apparent densities of tsetse flies and were located close to one of the three main rivers or an important tributary suggesting an important role of the remaining riverine vegetation in harbouring tsetse. This finding was considered and appropriated in the planning of the tsetse control programme. Despite the presence of trypanosomal infections in cattle sampled at 18 sampling sites, the average PCV values were normal. This is attributed to the large proportion of trypanotolerant cattle (WASH) and to some extent the Sanga breed in the sample.

The average prevalence of anti-trypanosomal antibodies in the study area was $19 \%$. This is in line with the $24 \%$ observed in the Savelugu District in the Northern Region of Ghana (Mahama et al., 2004). It is not surprising that the prevalence of anti-trypanosomal antibodies is substantially higher than the parasitological prevalence. This is partly due to the low sensitivity of parasitological diagnostic methods for trypanosomosis (Marcotty et al., 2008) especially in trypanotolerant cattle where parasitaemia is usually very low (Naessens, 2006) and the persistence of anti-trypanosomal antibodies in the absence of infection (Bocquentin et al., 1990; Van den Bossche et al., 2000). Hence, some of the seropositive but parasitologically negative animals are likely to be infected with trypanosomes (false negatives) whereas others may have been infected but have, for example, been treated. It is difficult to allocate a seropositive animal to one of those two categories.

However, on the basis of the PCV of an animal with anti-trypanosomal antibodies, assumptions can perhaps be made on its infection status. A typical sign of bovine trypanosomosis is anaemia which is best measured by determining the PCV (Murray and Dexter, 1988). The lower average PCV of seropositive Sanga breed suggests that a proportion of the seropositive animals of this breed is or has recently been infected with trypanosomes resulting in a reduced PCV. The absence of such a relationship in the WASH may not be surprising since they are trypanotolerant and thus support trypanosomal infections without impact on their health (Naessens, 2006). Surprisingly, no such relationship was observed in the Zebu cattle. This may be due to the frequent use of trypanocidal drugs in this very susceptible breed. These observations again demonstrate the value of indirect test such as the anti-trypanosomal antibody detection ELISA to improve the accuracy of trypanosomosis surveys especially in areas where trypanotolerant livestock is present.

\section{Conclusion}

G. tachinoides and G. palpalis gambiensis are the main vectors of trypanosomosis in the Upper West Region of Ghana. Entomological surveys conducted along the three main river systems suggest a possible southward retreat of the tsetse fly. However, trypanosomosis remains widespread in the Upper West Region, with the predominance of infections by $T$. vivax and, to a lesser extent, T. brucei.

The findings of the present study enabled an integrated tsetseelimination strategy to be developed, which combines aerial spraying (Sequential Aerosol Technique-SAT), ground spraying, insecticide treated targets and cattle pour-on. Implementation started in the period March-May 2010 with SAT operations, conducted along the three main rivers. SAT is being followed by targeted, selective deployment of the other control techniques.

\section{Acknowledgements}

This research work was funded by the African Union through the Pan-African Tsetse and Trypanosomosis Eradication Campaign (PATTEC)/Ghana under the tutelage of CIRDES/Burkina Faso, for which we are very much grateful. We also acknowledge the entire technical staff of PATTEC/Ghana and the Veterinary Services Directorate of Ghana for their immense contribution in the field of data collection. FAO, in the framework of the Programme against African Trypanosomosis (PAAT), provided technical assistance to this research through the project "Pro-poor Integrated Packages to Enhance Policy and Decision Making against the African Animal Disease Burden in sub-Saharan Africa" (GCP/RAF/442/IFA), funded by the International Fund for Agricultural Development (IFAD). Finally, we would like to acknowledge posthumously the immense contribution and encouragement we received from Professor Peter Van den Bossche who was the main collaborator in writing this paper but met his untimely demise shortly after we had submitted this paper the first time for publication.

\section{References}

Bengaly, Z., Ganaba, R., Sidibe, I., Duvallet, G., 1998. Infections trypanosomiennes chez des bovins dans la zone Sud-soudanienne du Burkina Faso. Revue D’Elevage et de Médecine Vétérinaire Des Pays Tropicaux 51, 225-229.

Bocquentin, R., Very, P., Duvallet, G., 1990. Cinétique des anticorps après traitement trypanocide chez des bovins infectés expérimantalement ou naturellement. Intérêt épidémiologique. Revue D’Elevage et de Médecine Vétérinaire Des Pays Tropicaux 43, 479-483.

Buxton, P.A., 1955. The natural history of tsetse flies. H.K. Lewis \& Co. Ltd., London Cannon, R.M., Roe, R.T., 1982. Livestock disease surveys. A field manual for Veterinarians. Australian Government Publishing Service, Canberra.

Cecchi, G., Courtin, F., Paone, M., Diarra, A., Franco, J.R., Mattioli, R.C., Simarro, P.P., 2009. Mapping sleeping sickness in Western Africa in a context of demographic transition and climate change. Parasite 16, 99-106.

Challier, A., 1973. Ecologie de Glossina palpalis gambiensis Vanderplank, 1949 en savane d'Afrique Occidentale. Mémoire de l'ORSTOM 64, 1-274.

Challier, A., Eyraud, M., Lafaye, A., Laveissière, C., 1977. Amélioration du rendement du piège biconique pour glossines (Diptera, Glossinidae) par l'emploi d'un cône inférieur bleu Cahier. O.R.S.T.O.M., Série Entomologie Médicale et Parasitologie $15,283-286$

Courtin, F., Sidibé, I., Rouamba, J., Jamonneau, V., Gouro, A., Solano, P., 2009. Impacts observés des évolutions démo-climatiques sur la répartition spatiale des hommes, des tsé-tsé et des trypanosomoses en Afrique de l'Ouest. Parasite $16,3-10$.

de La Rocque, S., Augusseau, X., Guillobez, S., Michel, V., De Wispelaere, G., Bauer, B., Cuisance, D., 2001. The changing distribution of two riverine tsetse flies over 15 years in an increasingly cultivated area of Burkina Faso. Bulletin of Entomological Research 91, 157-166.

Desquesnes, M., Bengaly, Z., Millogo, L., Meme, Y., Sakande, H., 2001. The analysis of the cross-reactions occurring in antibody-ELIZA for the detection of trypanosomes can improve identification of parasite involved. Annals of Tropical Medicine and Parasitology 95, 141-155.

Ford, J., 1971. The role of the trypanosomiasis in African ecology - A study of the tsetse fly problem. Oxford University Press, London.

Guerrini, L., Bord, J.P., Ducheyne, E., Bouyer, J., 2008. Fragmentation analysis for prediction of suitable habitat for vectors: example of riverine tsetse flies in Burkina Faso. Journal of Medical Entomology 45, 1180-1186. 
ARTICLE IN PRESS

Y. Adam et al./Research in Veterinary Science $x x x$ (2011) $x x x-x x x$

7

Laveissière, C., 1976. Ecologie de Glossina tachinoides Westw. En savanne humide de l'Afrique de l'ouest. VIII. Lieux de repos diurnes, variations saisonnières. Cahier ORSTOM Série Entomologie Médicale et Parasitologie 17, 181-191.

Mahama, C.I., 2005. The impact of land use and environmental change on the prevalence and incidence of bovine trypanosomosis in northern Ghana. Ph.D. thesis, University Liège.

Mahama, C.I., Mohammed, H.A., Abavana, M., Sidibé, I., Koné, A., Geerts, S., 2003. Tsetse and trypanosomoses in ghana in the twentieth century: a review. Revue D’Elevage et de Médecine Vétérinaire Des Pays Tropicaux 56, $27-$ 32.

Mahama, C.I., Desquesnes, M., Dia, M.L., Losson, B., De Deken, R., Geerts, S., 2004. A cross-sectional epidemiological survey of bovine trypanosomosis and its vectors in the Savelugu and West Mamprusi districts of northern Ghana. Veterinary Parasitology 122, 1-13.

Marcotty, T., Simukoko, H., Berkvens, D., Vercruysse, J., Praet, N., Van den Bossche, P., 2008. The use of the PCV-value in the diagnosis of trypanosomal infections in cattle. Preventive Veterinary Medicine 87, 288-300.

Murray, M., Murray, P.K., Mcintyre, W.I.M., 1977. An improved parasitological technique for the diagnosis of African trypanosomiasis. Transactions of the Royal Sociey of Tropical Medicine and Hygiene 71, 325-326.

Murray, M., Dexter, T.M., 1988. Anaemia in bovine African Trypanosomiasis: a review. Acta Tropica 45, 389-432.

Naessens, J., 2006. Bovine trypanotolerance. a natural ability to prevent severe anaemia and haemophagocytic syndrome? International Journal for Parasitology 36, 521-528.
Nash, T.A.M., 1948. Tsetse flies in British West Africa: the Gold Coast. Her Majesty Stationary Office, London, UK.

Offori, E.D., 1964. Tsetse flies in Ghana. Ghana Journal of Science 4, 1-8.

Shaw, A., Hendrickx, G., Gilbert, M., Mattioli, R., Codjia, V., Dao, B., Dial, O., Mahama, C., Sidibe, I., Wint, W., 2006. Mapping the benefits. DFID-AHP/FAO-PAAT.

Simarro, P.P., Cecchi, G., Paone, M., Franco, J.R., Diarra, A., Ruiz, J.A., Fèvre, E.M., Courtin, F., Mattioli, R.C., Jannin, J.G., 2010. The Atlas of human African trypanosomiasis: a contribution to global mapping of neglected tropical diseases. International Journal of Health Geographics 9, 57.

Solano, P., Bouyer, J., Itard, J., Cuisance, D., 2010. Cyclical vectors of Trypanosomosis In: Lefèvre, P.C., Chermette, J., Blancou, R., Uilenberg, G. (Eds.), Infectious and Parasitic Diseases of Livestock. CABI.

StataCorp., 2009. Stata Statistical Software: Release 10.0. Stata Corporation, Texas. Swallow, B., 2000. Impacts of Trypanosomiasis on African Agriculture. FAO, Rome. Van den Bossche, P., Chigoma, D., Shumba, W., 2000. The decline of antitrypanosomal antibody levels in cattle after treatment with trypanocidal drugs and in the absence of tsetse challenge. Acta Tropica 77, 263-270.

Van den Bossche, P., de La Rocque, S., Hendrickx, G., Bouyer, J., 2010. A changing environment and the epidemiology of tsetse-transmitted livestock trypanosomiasis. Trends in Parasitology 26, 236-243.

Wint, G.R.W., Rogers, D. (2000). Predicted distributions of tsetse in Africa. Food and Agriculture Organization of the United Nations.

Wint, G.R.W. (2001). Kilometre resolution Tsetse Fly distribution maps for the Lake Victoria Basin and West Africa. Food and Agriculture Organization of the United Nations/International Atomic Energy Agency.

Please cite this article in press as: Adam, Y., et al. Bovine trypanosomosis in the Upper West Region of Ghana: Entomological, parasitological and serolog-

ical cross-sectional surveys. Res. Vet. Sci. (2011), doi:10.1016/j.rvsc.2011.04.004 